\title{
From Venture Idea to Venture Opportunity
}

\author{
Peter Vogel
}

Opportunities are a core construct in the field of entrepreneurship. Despite recent advances suggesting the separation of ideas from opportunities, the field still suffers from conceptual deficiencies. This article builds on this distinction and leverages insights from creativity and innovation management literature to propose a framework that allows tracing the evolution of a venture from first insight to exploitation. It discusses real-time/longitudinal and retrospective measurement techniques from the fields of entrepreneurship, creativity, and innovation management to empirically capture the framework. Several research questions for future studies are provided, concluding with a discussion of implications for research and practice.

\section{Introduction}

As emphasized in recent publications (e.g., Short, Ketchen, Shook, \& Ireland, 2010), the field of entrepreneurship has experienced a rapid increase in scholarly research examining the role of opportunities in new venture creation. Against the backdrop of mostly individual-level explanations of entrepreneurial phenomena, it was the work of Venkataraman (1997) and Shane and Venkataraman (2000) which suggested that an improved understanding of processes and outcomes in new venture creation can be attained once both the individual and the opportunity are taken into consideration. Undoubtedly, the field would not be where it is today if it were not for the focused analysis of what the enterprising individuals are actually acting upon-that is, the opportunity (Dencker, Gruber, \& Shah, 2009a, 2009b; Venkataraman, Sarasvathy, Dew, \& Forster, 2012).

Yet, despite the fact that opportunities are a core concept within the field of entrepreneurship, research on opportunities is still in a developmental stage (Dimov, 2007b; Hill \& Birkinshaw, 2010), as evidenced in a number of recent publications (e.g., Alvarez \& Barney, 2013; Eckhardt \& Shane, 2013; Garud \& Giuliani, 2013; Shane, 2012; Venkataraman et al., 2012), requiring further theorizing before key advances in our understanding of opportunities and, more broadly, the early stages of the entrepreneurial process can be achieved (e.g., Davidsson, 2012; Hill \& Birkinshaw).

More specifically, scholars have observed that the field still lacks construct clarity (Suddaby, 2010) and an appropriate unit of analysis for empirical studies, causing a "serious disconnect between theory and empirical examinations" (Hansen, Shrader, \& Monllor, 2011, p. 7) thus preventing scholars from advancing in a constructive and collaborative manner (Hill \& Birkinshaw, 2010). In addition, critics have observed that scholars

Please send correspondence to: Peter Vogel, tel.: +41 7122472 06; e-mail: peter.vogel@unisg.ch. 
tend to use indeterminate or even undefined constructs in their research on opportunities, which leaves their focal study object vague. In this vein, Hansen et al. (p. 4) note that "many conceptual papers failed to offer definitions and even many empirical papers failed to describe operationalizations or provide definitions." However, a significant level of confusion exists not only with respect to the definition of opportunities but also the nature of opportunities, with some suggesting that they are a direct result of momentary insights (e.g., discovery) while others adopt a process perspective (e.g., creation).

Taken together, these conceptual problems hinder research in two main ways. First, they make it difficult for scholars to compare results across studies, to synthesize existing findings, to cleanly delineate the frontier of research on opportunities in entrepreneurship and, thus, to move the field forward with their own research. Second, the lack of conceptual clarity means that scholars face significant challenges in testing current theories on opportunities, which further limits the field's ability to substantiate theoretical debates with empirical results and to make progress in scientific discourse. Given these problems, it is hardly surprising that a number of scholars have recently pointed out that research on opportunities is still in a developmental stage and requires further theorizing before key advances in our understanding of opportunities and, more broadly, the early stages of the entrepreneurial process can be achieved (e.g., Davidsson, 2012; Hill \& Birkinshaw, 2010). These challenges are also evident in current typologies. For instance, a review of the 12 most influential typologies on opportunities (cf. Table 1) indicates that the majority of existing typologies do not build on the logic that venture ideas and venture opportunities are distinct constructs and that opportunities are developed from an initial idea over time.

This article argues that one main reason as to why progress in scholarly understanding of opportunities has been hindered is that the majority of prior work has not distinguished between the constructs of venture ideas and venture opportunities. This goes in line with what Dimov (2007b, p. 717) has recently argued: "the main deficiency of this line of research is the conceptual collapse of the time between a first insight and the [opportunity] that ends up being implemented." It is this temporal collapse that prevents scholars from tracing the evolution of an initial idea through to the incubation process where the initial idea is being shaped and refined and missing information is being collected until the prospective entrepreneur evaluates it as both desirable and feasible to launch a venture. I argue that the prevailing terminological confusion surrounding opportunities (e.g., discovery vs. creation) in part stems from this temporal collapse. The fact that entrepreneurship research still suffers from a lack of sufficiently fine-grained concepts is surprising given that early work in the field proposed that the entrepreneurial process could be viewed as a progression from an initial idea to an opportunity, to venture installation and growth (e.g., Churchill \& Lewis, 1983).

These observations become even more pertinent when one considers the neighboring literature in creativity and innovation management, where the commonly held view is that an idea needs to be further developed and refined until a product or service offering is available that can be commercialized on the marketplace (e.g., Amabile, Conti, Coon, Lazenby, \& Herron, 1996; Afuah, 2003). Case in point, creativity is defined as the process of bringing into being ideas that are both novel and useful (Amabile, 1996; Sternberg \& O'Hara, 1999). However, not all ideas are creative in nature as they represent "pre-inventive forms that may or may not lead to a creative product or service as they are explored, modified, transformed, extended, or even rejected on the basis of additional exploratory thought processes" (Ward, 2004, p. 179). Following a similar perspective, the innovation management literature views the development of new products as the combination of idea generation (the "fuzzy frontend") and a stage-gate process of shaping and refining initial ideas until market launch 


\section{Most Influential Typologies on Entrepreneurial Opportunities (in Chronological Order)}

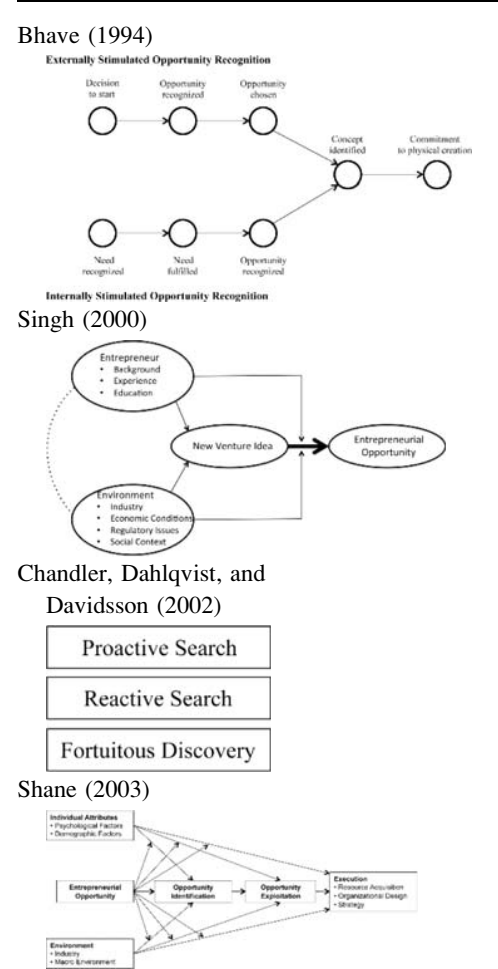

Ardichvili, Cardozo, and Ray (2003)

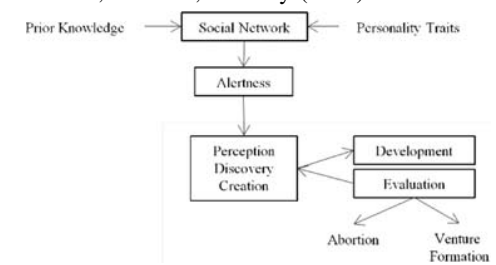

Chandler, DeTienne,

and Lyon (2003)

\begin{tabular}{|c|}
\hline Proactive Search \\
\hline Problemistic Search \\
\hline Fortuitous Discovery \\
\hline Opportunity Creation \\
\hline
\end{tabular}

Lumpkin, Hills, and

Shrader (2004)

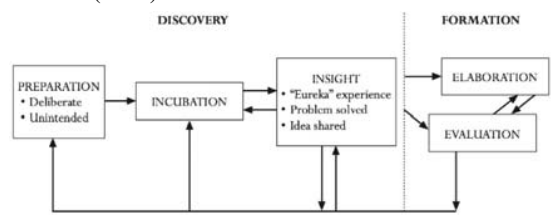

- Process model of entrepreneurial venture creation.

- Differentiates between different "triggers": internally versus externally stimulated.

- Different paths to arrive at opportunity.

- Does not include the concept of a venture idea.

- Discusses further stages, including to execution.

- Typology visualizes influence of individual and environment factors on idea and opportunity.

- Does not consider triggers and paths to ideas.

- Unrecognized opportunities exist, but it takes the right person, in the right environment to develop an idea that can result in a recognized opportunity.

- Taxonomy introduces different approaches to opportunity recognition, including proactive, reactive, and fortuitous search.

- Serves as a basis for the proposed framework

- Framework based on individual-opportunity nexus.

- An opportunity is present in combination with individual and environmental factors.

- An individual identifies opportunities and exploits it.

- Refinement of "opportunity recognition" into (a) perception of need, (b) discovery of possible fit, and (c) creation of fit through establishment of concept.

- Key influencers: alertness, prior knowledge, opportunity discovery, social network, and personality.

- Does not consider venture ideas.

- Four distinct opportunity development processes: (1) proactive search, (2) problemistic search, (3) fortuitous discovery, and (4) opportunity creation.

- Serves as a basis for the proposed framework.

- Based on the five-phase framework of the creative process by Csikszentmihalyi (1996), the authors present a two-stage model of discovery and elaboration as part of opportunity recognition.

- Serves as a basis for the proposed framework. 


\section{Table 1}

\section{Continued}

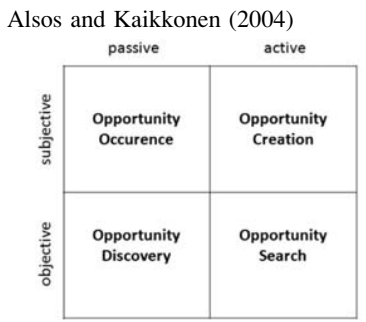

Smith, Matthews, and Schenkel (2005)

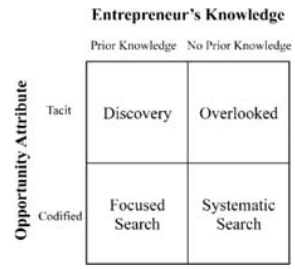

McMullen and Shepherd (2006)

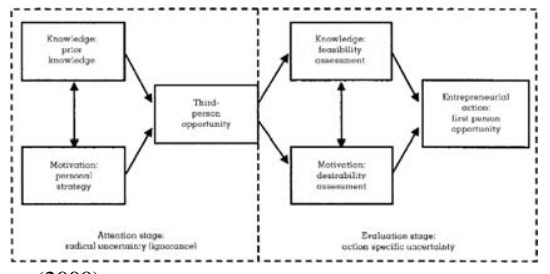

Dew $(2009)$

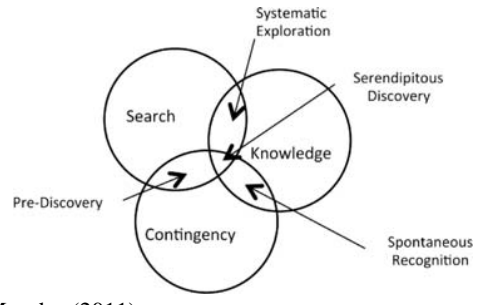

Murphy (2011)

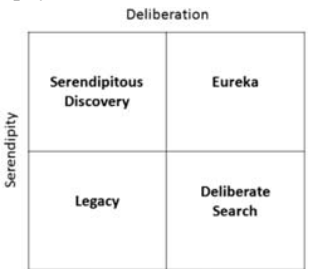

Davidsson (2012)

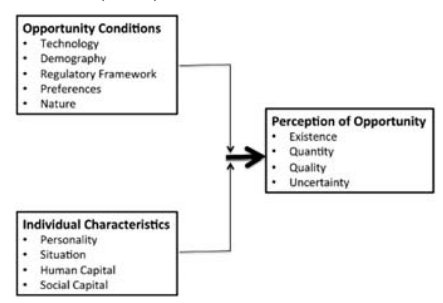

- $2 \times 2$ typology based on "active/passive" and "objective/subjective."

- Four avenues to opportunities: occurrence, creation, discovery, and search.

- No temporality in the model.

- Venture ideas not part of the model.
- $2 \times 2$ model based on type of opportunities (either tacit or codified) as well as the existence of prior knowledge on an individual level.

- Four avenues identified.

- No temporality in the model.

- Venture ideas not part of the model.
- A model of entrepreneurial action that describes how an individual develops a third-person opportunity (an opportunity for everyone) to a firstperson opportunity (an opportunity for me).

- Evaluation stage consists of feasibility and desirability assessment.

- Serves as a basis for the proposed framework.
- Typology to conceptualize serendipity as a combination of search, prior knowledge, and contingency.

- Four distinct paths: (1) systematic exploration, (2) spontaneous recognition, (3) pre-discovery, and (4) serendipity in the center.

- No temporality in the model.

- Venture ideas not part of the model.
- $2 \times 2$ typology based on "serendipity" and "deliberation."

- Four avenues to opportunities: serendipitous discovery, eureka, legacy, and deliberate search.

- No temporality in the model.

- Venture ideas not part of the model. 
(Cooper, 1988; Jolly, 1997). As Afuah (p. 13) explains: "Generating good ideas or adopting a new one, in and of itself, is only the start. To be innovation, an idea must be converted into a product or service that customers want."

Against the backdrop of these observations, the present study sets out to develop an empirically testable framework coupled with definitions and suitable measures which, together, allow scholars to obtain a clearer understanding of the early stages of the venture creation process. More specifically it temporally disentangles venture ideas from venture opportunities and leverages existing insights from the creativity and innovation management literature to substantiate the development of the proposed framework. One goal of this article is to help entrepreneurship scholars resolve some of the pertinent issues and debates and to lay a foundation for future collaborative advancements as a distinct scientific discipline (Davidsson, 2012; Dimov, 2007a; Shane, 2012).

The present article contributes to theory within the domains of entrepreneurship as well as the neighboring domains of creativity and innovation management. It also contributes to practice. First, by building on earlier studies that call for a distinction between ideas and opportunities, this article provides a novel, empirically testable framework which outlines the early phase of the new venture creation process, and creates finegrained distinctions between core constructs. It embraces the notion that opportunities should not be seen as single insights, but rather as emerging from the continuous shaping and refining of (raw) venture ideas. Second, the article defines and operationalizes each of the proposed constructs within the framework (including validated construct measures for both real-time/longitudinal and retrospective research) and offers several research questions which may guide future studies. In doing so, this article answers recent calls for more clearly defined and empirically testable conceptualizations. Third, this article builds on recent advances in the neighboring fields of creativity and innovation management research to offer more refined sets of concepts, methods, and measures for studying the early phase of new venture creation. Likewise, the fields of creativity and innovation management can also benefit from insights in the entrepreneurial arena, given that the context of new ventures is less complex. Fourth, the article suggests a novel unit of analysis, the venture concept, which allows scholars to trace the evolution of the new venture from raw idea to opportunity, exploitation, and beyond. We base this focal construct on the influential work of Abell (1980) in defining the core dimensions that characterize a business. Specifically, Abell argues that a business can be defined along three primary dimensions: the customer segment being addressed, the customer need being addressed, and the resources and capabilities being used to produce the offering. This concept represents an early-stage equivalent of the much more refined business model, which comes into play at a later stage, once more refined elements such as "value proposition" or "distribution channels" become more evident to the founders.

The article will proceed as follows. After introducing the framework and its main components, I will discuss research design and measurement techniques for each of the constructs presented in the framework, including retrospective and real-time/longitudinal measurement techniques. Then, I will present some promising research questions which scholars may seek to empirically address in the future. The article closes with a discussion and implications for theory and practice.

\section{From Idea to Opportunity: A Conceptual Framework}

By drawing inspiration from innovation and creativity research (e.g., Amabile et al., 1996; Afuah, 2003; Kornish \& Ulrich, 2014; Schilling, 2013) and by building on both 
Figure 1

\section{Conceptual Framework}

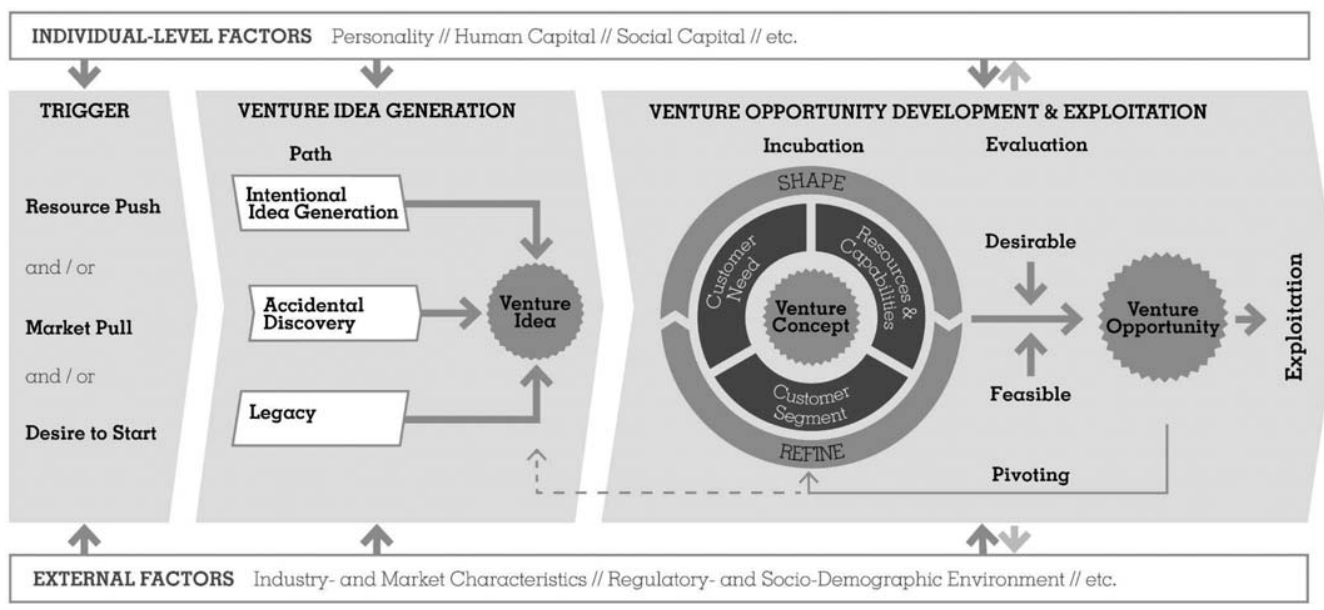

aforementioned set of observations and earlier typologies (cf. Table 1) on opportunities (e.g., Ardichvili et al., 2003; Bhave, 1994; Dew, 2009; Murphy, 2011), I develop a dynamic and iterative framework which specifies the early-stage entrepreneurial process from venture idea to venture opportunity (Figure 1). This framework is composed of several core elements, including the triggers of idea generation, the idea-generation paths, the stages of incubation and evaluation as part of the opportunity development stage, and ultimately exploitation. What the framework also includes are both individual-level and external factors that influence and interact with each of the stages of the process.

The initial idea (or multiple ideas) may vary considerably in scope, complexity, and completeness depending on what triggered idea generation and on the individual- and external factors. ${ }^{1}$ Consequently, the incubations stage will also vary considerably in duration and complexity. While some entrepreneurs may start with a clear idea of what their offering, targeted customer segment, pricing, and distribution channels might look like, others might start with "only" a novel technology but no clear understanding of what it may be used for; whom might be a potential customer; and how it will be produced, sold, or distributed. Along the same lines, evaluation (desirability and feasibility) is dependent on a number of individual-level and external factors (McMullen \& Shepherd, 2006). The exploitation of a specific opportunity might be attractive for one person but not for another and there might be better settings (e.g., geographical, economical, political) to exploit a specific opportunity. That being said, two individuals will most likely evaluate the same venture concept differently with all other factors being the same, and one individual will evaluate it differently in different circumstances and contexts. Hence, the entrepreneurial process does not take place in isolation but is embedded in the social and environmental context of the entrepreneur.

1. Individual-level factors take into account both single founders as well as founding teams. 
In the following, I will examine the core elements and stages of the framework and provide definitions and illustrative examples. Next, venture ideas, venture concepts, and venture opportunities will be defined.

\section{Defining Venture Ideas, Venture Concepts, and Venture Opportunities}

To define the key constructs venture ideas, venture concepts, and venture opportunities, it is instructive to build not only on definitions that have been put forward in entrepreneurship research, but also to turn to related work in innovation management, as scholars in this domain have grappled with similar conceptual challenges in the past. In particular, innovation scholars have found it useful to distinguish between early insights or artifacts (often referred to as ideas, prototypes, or inventions) and the concept of innovation. The latter incorporates the commercialization of the product on the marketplace, including both business-related considerations and the favorable reception of the product by customers (Jolly, 1997; Schilling, 2013). Notably, these distinctions have allowed scholars to focus their research efforts on specific stages within the innovation process (e.g., the fuzzy front-end and idea generation), to form dedicated research communities around them, and to develop significant bodies of knowledge on the overarching innovation process.

In making these conceptual distinctions, I not only acknowledge their temporal distention but also adopt an "action-perspective" (Dimov, 2007b; McMullen \& Shepherd, 2006; Venkataraman et al., 2012), which indicates that an initial venture idea forms a necessary but not sufficient condition for a venture opportunity to emerge. To have sufficient information for a well-informed evaluation as to whether or not there is an attractive opportunity for a future venture, it takes the action of the entrepreneur, who forms substance around the initial idea by collecting missing knowledge on the various dimensions of the venture concept. In the following, I will define the three core constructs of this article: venture ideas, venture concepts, and venture opportunities. The venture concept forms the central element of the framework and because both the definitions of the venture idea and that of the venture opportunity relate to the definition of the venture concept, I will first provide the definition of the venture concept, followed by that of the temporally anteceding venture idea.

Venture Concept. The venture concept represents a nascent-stage form of a business model (Afuah \& Tucci, 2000; Chesbrough \& Rosenbloom, 2002; Osterwalder \& Pigneur, 2010). At this stage, entrepreneurs mostly have only a vague understanding of the different components of their future venture. Before having a final product or service or before having spoken with prospective clients, suppliers, or partners, many of the elements are preliminary in nature.

Building on Abell (1980), the venture concept is composed of three overarching dimensions, namely the customer segment, the customer need, and the entrepreneurs' resources and capabilities (including the specific product/service/offering). Typically, it is only later that more detailed, second-order elements of a business model are being elaborated (e.g., a well-articulated value proposition, pricing strategy, distribution channels, etc.).

The venture concept can be regarded as the "glue" of the framework, connecting venture ideas and venture opportunities. What makes this approach particularly useful for scholars is that it allows them to use a holistic perspective on the entrepreneurial process and trace the venture's evolution from idea to opportunity and exploitation over a period of time (in particular when using real-time measures, cf. Table 3). Consequently, the 
venture concept constitutes the framework's core unit of analysis (Davidsson \& Wiklund, 2001) and I define it as the simplified nascent-stage representation of a business model, including the customer segment, the customer need, and the resources and capabilities employed in the future venture.

Venture Idea. Building on the above, I define a venture idea as a preliminary and mostly incomplete mental representation of the concept for a potential future venture. This initial mental representation of the venture concept typically represents a vague insight with respect to some potential for value creation (Kornish \& Ulrich, 2014). Following the three dimensions of the venture concept discussed above, such insights may relate to, for instance, an unmet customer need (e.g., long battery life in smart phones), a particular customer segment (e.g., senior citizens), a resource or capability (e.g., new type of waterabsorbing material), or a combination of these elements. However, the individual has yet to understand how value can be created and how the commercial potential of the initial idea can be exploited. With reference to the creativity and innovation literature (e.g., Girotra, Terwiesch, \& Ulrich, 2010), I will later discuss different characteristics of ideas (e.g., quantity, quality and diversity, cf. Table 3 ) and relate different stages of the framework to these characteristics.

Venture Opportunity. At some point, the individual will evaluate whether it is worthwhile to move to exploitation. The degree of elaboration of the venture concept, at the point where the entrepreneur evaluates it as being a desirable and feasible opportunity for a new venture, may vary considerably from case to case. Some of the most interesting and path-breaking venture opportunities may have come into being because they were not or could not be understood well enough to be specified during venture concept incubation (George \& Bock, 2012).

The proposed definition of a venture opportunity emphasizes that prospective entrepreneurs will act based on their beliefs of what can be accomplished in the future (McMullen \& Shepherd, 2006; Sarasvathy, Dew, Velamuri, \& Venkataraman, 2010). This is a notion that is also common to innovation literature (Afuah, 2003; Jolly, 1997), as it is the expectations of the future and not the objective facts that determine a firm's behavior (Penrose, 1959). However, given that an entrepreneur does not act in isolation but instead within a given market environment, certain objective and external elements must be considered when talking about venture opportunities. Thus, by drawing on this work and work of McMullen and Shepherd and Short et al. (2010), I define a venture opportunity as a favorable combination of endogenously shaped and exogenously given circumstances that make it both desirable and feasible for the entrepreneur to exploit a venture concept and to introduce a potentially value-adding offering into the marketplace.

Having introduced definitions of the core constructs, I will next discuss the different stages of the framework, beginning with the triggers of idea generation.

\section{Triggers of Venture Idea Generation}

The role of triggers of idea generation has received significant attention from creativity and innovation scholars, and also has garnered the interest of some entrepreneurship researchers (Bhave, 1994). Typically, the literature in these domains has studied idea generation as a result of either a recognized customer segment or customer need ("market pull"; Brown, 2008; Smith, 1998) or a resource that is to be commercialized ("resource 
push"; Jolly, 1997). ${ }^{2}$ Regarding the latter, entrepreneurship scholars highlight the key role that effectuation (Sarasvathy, 2001) and bricolage (Baker \& Nelson, 2005) can play in new venture creation, as individuals may start their entrepreneurial efforts by seeking to use the resources they have at hand for productive purposes. Beyond the traditional classification of resource push and market pull, people may also engage in new firm creation simply because of their desire to be an entrepreneur, without yet knowing specifically what they are going to do (in the proposed model I call this trigger desire to start). Entrepreneurship appears to be a desirable career for many individuals, particularly young people (Sieger, Fueglistaller, \& Zellweger, 2014). However, many do not know how to get started and how to generate a useful venture idea. Following this desire, they might generate an idea based on one of the subsequently introduced paths, be it intentional idea generation, accidental discovery, or legacy.

It is important to note that idea generation rarely happens in a void. Ideas oftentimes build on already existing own ideas ("idea sets"; Hill \& Birkinshaw, 2010) as well as other peoples' ideas. Hence, the initial venture idea that forms the starting point of the described process (Figure 1) is likely to be the product of previous variations of ideas (Weick, 1989), oftentimes taking considerable time to form in the individual's mind. This article differentiates three types of triggers for venture ideas (Figure 1): resource push, market pull, and desire to start. ${ }^{3}$

\section{Paths of Venture Idea Generation}

Idea generation is not a unitary process (e.g., Ward, 2004). As Smith (1998) and other scholars from creativity research point out, people have different ways of generating ideas, which is one of the main reasons as to why the entrepreneurship field currently suffers from a confusion in terminology. In reviewing 150 articles on opportunities, I counted no less than 21 terms that have been used to describe this step including, among others (cf. Table 2), discovery (Kaish \& Gilad, 1991; Kirzner, 1997), creation (Alvarez \& Barney, 2007; Sarasvathy, 2001), identification (Ardichvili et al., 2003; Gaglio \& Katz, 2001), search (Ardichvili et al.; Murphy, 2011), serendipity (Dew, 2009; Murphy), and recognition (Baron, 2006; Dew).

By aggregating these different terms, by synthesizing existing findings in creativity research, and by combining these insights with the aforementioned triggers, I derive three distinct paths by which entrepreneurs generate their venture ideas. In the following, I will briefly discuss each path and provide illustrative cases.

Intentional Idea Generation. This approach represents cases where the individual is actively engaged in venture idea generation as a result of one or more specific triggers: searching for an idea because of the desire to start a new venture, searching for an idea on how a given resource could be commercialized, or searching for an idea on how an unfulfilled customer need could be addressed (Jolly, 1997). While some scholars have discussed this general approach in the field of entrepreneurship (e.g., DeTienne \& Chandler, 2004; Marvel, 2013), intentional idea generation has received the strongest interest from creativity researchers, who have developed an armamentarium of techniques that can be used to assist in this process (Smith, 1998). This includes brainstorming, where one starts

2. Resource push may also include the stock of already available ideas that may trigger the generation of new ideas.

3. These triggers are not mutually exclusive. There may be conditions where more than one trigger exist. 
Alphabetic List of Terms Previously Used in the Context of Opportunities

Active search

Identification

Problemistic search

Abduction
Creation
Deliberate search
Development
Discovery
Eureka

Legacy

Matching

Passive search

Pre-discovery

Proactive search

Problem-solving

\author{
Recognition \\ Serendipity \\ Serendipitous discovery \\ Spontaneous recognition \\ Systematic exploration \\ Tinkering
}

off by freely generating ideas (Osborn, 1942); wishful thinking, where one starts off at the ideal outcome and tries to figure out how to get there (e.g., commercial space flight) (Ward, 2004); or design thinking, where one starts with a problem and uses design and creativity techniques, and convergent/divergent thinking to come up with the best solution (Brown, 2008).

The founders of excite.com offer a good example for choosing this path as they first had the desire to become entrepreneurs and only then looked for potential ideas. Or, consider the case of Stratasys, one of the first 3D printing companies, who proactively sought out specific market needs for their novel and innovative technology (Pederson, 2005).

Accidental Discovery. Unlike cases of intentional idea generation, accidental discovery refers to those cases where the generation of venture ideas happens unintentionally. The entrepreneur generates the idea not because he or she is specifically engaged in idea generation but purely by accident. This might happen, for example, while looking for something else or even not looking for anything specific.

A good example is Alfred Nobel, the inventor of dynamite, who initially looked for a way to safely store nitroglycerine and one day accidentally discovered the absorbability of porous earth or kieselguhr. This led to the insight that when combining these two elements, they not only could be stored safely but also formed a stable explosive. Following his patent in 1867, he started commercializing what he called "Nobel's Blasting Powder" (Schück \& Sohlman, 1929).

Another good example is Will Keith Kellogg, who was preparing wheat dough to bake bread for patients at Battle Creek Sanitarium in Michigan. One day he forgot about the dough and left it sitting out for hours. When he came back, it had turned all flaky so that when he took it out of the oven, the dough had turned into crunchy flakes. The patients loved it and it occurred to him that he could make a business out of it (Jones, 2011).

Legacy. In early research on the origins of ideas, Koller (1988) found that while half the entrepreneurs generated their ideas themselves, the other half received their initial idea from someone else. Building on Murphy (2011), I label this mechanism "legacy" and define it as receiving a venture idea from someone else. Two forms of legacy can be distinguished, depending on whether or not the individual deliberately involved others.

The external search for ideas has received most attention from innovation scholars. For instance, open innovation and crowdsourcing have been suggested as systematic 
ways in which the knowledge of external individuals can be tapped for the identification of promising solutions (Afuah \& Tucci, 2012; Chesbrough, 2003). Yet, the notion that venture ideas can be sourced by engaging in external search has recently also been a subject of entrepreneurship studies (Gruber, MacMillan, \& Thompson, 2013; Ozgen \& Baron, 2007).

A good example is Jake Zien, the founder of Pivot Power. Starting from an identified problem, he engaged with a crowdsourcing portal (quirky.com) where multiple ideas were proposed, including the one that formed the nucleus for his flexible, surgeprotecting power strip, and ultimately, his venture. Another prominent example is Fred de Luca, founder of Subway. He needed money for college and approached a friend, Peter Buck, hoping for cash support. Instead, Peter told him to open a submarine sandwich shop and earn the money himself as an entrepreneur (CNBC, 2005).

Summary. These different examples illustrate the three paths of venture idea generation-intentional idea generation, accidental discovery, and legacy. Once an idea has been generated, the entrepreneur must take further actions to understand whether there is an opportunity to launch a successful venture based on the idea. In the following, I will elaborate on these steps.

\section{Venture Opportunity Development and Exploitation}

The opportunity development stage is both iterative and dynamic, encompassing learning under conditions of uncertainty and as a consequence of trial-and-error (Corbett, 2005; Dimov, 2007a; McGrath \& MacMillan, 2000). During the incubation stage, the entrepreneur will collect missing information and construct a more refined image of what the future venture might look like. More specifically, he or she will shape and refine the venture concept and its underlying first-order dimensions, namely the customer segment, the customer need, and the entrepreneur's resources and capabilities (Abell, 1980). While some second-order dimensions of a business model might already be present at this stage (e.g., most often a preliminary value proposition), it is typically only later, once the opportunity has been developed, that all second-order dimensions (e.g., detailed pricing strategy, the exact distribution channels, or a well-articulated value proposition) are clearly spelled out (Osterwalder \& Pigneur, 2011). During the incubation phase, the entrepreneur seeks to understand and test whether there is a "product-market fit" or whether adjustments need to be made to either the offering or the targeted customer segment. This is in line with recent thinking in the entrepreneurial domain, including the lean startup approach (Blank \& Dorf, 2012).

At this stage, it is critical that the entrepreneur gathers sufficient information for an informed decision as to whether or not it appears to be both desirable and feasible (Krueger, 1993; McMullen \& Shepherd, 2006) to move forward and launch a new venture or whether he or she will have to go back to incubation or even abandon the project altogether.

Incubation. Just as processes of innovation often occur "in nested and repeated cycles of variation, selection and retention" (Zbaracki, 1998: 612), the initial idea mostly forms a starting point from which different business-related aspects are fleshed out, evaluated, and refined until the entrepreneur possesses sufficient confidence in the creative potential of the venture. 
It requires time and effort to take an idea from the conceptual level to a state where it is ready for exploitation (Garud \& Giuliani, 2013; Van de Ven, Polley, Garud, \& Venkataraman, 1999). As Thomas Edison said, there are always difficulties arising after the initial idea is generated, and intense work is required before the commercial success — or failure — is reached (Friedel, Israel, \& Finn, 1986). For instance, an entrepreneur may have identified a customer segment that can be addressed by a given technology (i.e., resource push). Yet this resource-market linkage needs to be further elaborated (e.g., a refined value proposition, competitive advantage, costs, revenues) to understand whether the potential for establishing a successful venture exists. Consider James Dyson, who pioneered the "bagless" vacuum cleaner: 5 years and 5,127 prototypes after he noticed how conventional vacuum cleaners clogged with dust, he arrived at a solution which he then first licensed to incumbents before launching his own firm (Dyson, 2003).

In more general terms, this incubation cycle can be viewed as an entrepreneurial learning process, for accumulating missing information about the venture idea; for engaging in experiments (e.g., testing different pricing strategies); or for adapting, shaping, and refining the venture concept (Alvarez, Barney, \& Anderson, 2013; Corbett, 2005; Garud $\&$ Gehman, 2012). The accumulation of missing knowledge often involves the entrepreneur's social ties as a mechanism for developing a more complete venture concept (Hills, Lumpkin, \& Singh, 1997).

Evaluation. The evaluation of the venture concept forms an essential part of the incubation cycle and entails an assessment of "what will be," assuming one were to exploit the concept (Haynie, Shepherd, \& McMullen, 2009). While such an assessment is often based on thorough analysis (Ardichvili et al., 2003), the entrepreneur's confidence in the potential may be based on partial information only and as such, relies to a significant extent on intuition and the entrepreneur's wish to continue on the path taken (Sarasvathy et al., 2010). As Corbett (2005, p. 485) puts it: "The evaluation period is where the rubber meets the road. Csikszentmihalyi (1996) suggests that this stage is the most challenging because it requires entrepreneurs to be brutally honest with themselves: they must assess whether they have just a good idea or a truly viable business opportunity." Judging desirability and feasibility leads to what McMullen and Shepherd (2006) call a first-person opportunity_-"an opportunity for me."

Exploitation. As soon as the entrepreneur has accumulated sufficient information and knowledge to assess whether it is desirable and feasible to create a new venture based on the current venture concept, he or she will move toward exploitation. Exploitation "refers to building efficient, full-scale operations for products or services created by, or derived from, a business opportunity" (Choi, Lévesque, \& Shepherd, 2008).

Because entrepreneurs will differ in their level of preparation for the exploitation process (i.e., the amount of knowledge and information about the various dimensions of the venture concept) and in their belief in the correctness of their plans, they will also differ in the extent to which they will change and adapt their venture concept upon exploitation. As Choi et al. (2008) point out, a rapid exploitation with a lack of understanding of diverse dimensions of the venture concept can be both advantageous and disadvantageous. On the one hand, in uncertain conditions, it may grant the entrepreneur first-mover advantages to act quickly. On the other hand, haste may prevent the entrepreneur from sufficiently refining the product or offering or from sufficiently understanding the market prior to market entry, possibly requiring major modifications at a later stage. Yet, the willingness to experiment with different solutions and to pivot a venture upon entering the market, will vary from entrepreneur to entrepreneur (Ries, 2011). The concept of pivoting 
has gained momentum more recently in the context of the digital economy where entrepreneurs entering the market with minimal viable products (MVPs), fail quickly and cheaply, to adapt the offering as they penetrate the market. This approach is best explained by the following metaphor: "jumping off the cliff and assembling the plane on the way down" (Reid Hoffman). This approach is in stark contrast to the traditional innovation and new product development processes of established organizations where innovation takes place in secrecy and suddenly appear on the market without having included the prospective customers in the development process (Vogel \& Fischler-Strasak, 2014).

Having introduced all stages and constructs of the framework, I will next discuss research design and measures that will allow scholars to empirically capture each of these constructs.

\section{Research Design and Construct Measurement}

Critics have observed that entrepreneurship research is still experiencing a "serious disconnect between theory and empirical examinations" (Hansen et al., 2011, p. 7). This observation holds particularly true for research on opportunities, which is still in "a fairly embryonic stage" (Hill \& Birkinshaw, 2010, p. 85) and needs more solid and empirically testable constructs (Suddaby, 2010).

In that this framework temporally distends this earliest phase of the entrepreneurial process and introduces the venture idea, the venture concept, and the venture opportunity as three separate, yet inter-related constructs, it provides scholars with more refined units of analysis and a basis for both cross-sectional and longitudinal research. Empirical assessment is, however, far from trivial, because it entails the challenge of capturing relatively fine-grained data to understand the development process from a raw venture idea to a venture concept and, finally, to a venture opportunity. Scholars thus will need to use sophisticated methods and measures to capture the underlying constructs in reliable ways (Crook, Shook, Morris, \& Madden, 2010). Although entrepreneurship scholars have begun to measure venture ideas (Hill \& Birkinshaw), the fields of creativity and innovation management both provide a much greater wealth of insights on how idea generation and evaluation can be examined in a rigorous fashion. For instance, Cropley (2000) identified at least 255 tests for measuring creativity, many of which are directly linked to the assessment of ideas (i.e., quantity, quality, or variety of ideas). Moreover, capturing the evolution of an initial idea and its trigger into an opportunity and beyond, requires the use of real-time/longitudinal study designs which are far from trivial and much less common in organizational research (McMullen \& Dimov, 2013; Ployhart \& Vandenberg, 2010; Selden \& Fletcher, 2015). Table 3 provides a detailed overview of both real-time and retrospective measurement techniques to capture the core constructs of each of the three phases of the framework, with phase 1 being "triggers and venture idea generation," phase 2 being "venture opportunity development," and phase 3 being "exploitation." Next, I will present several retrospective and real-time research designs, followed by these three phases and finally, associated research designs.

\section{Retrospective and Real-Time Research Designs}

While retrospective research designs (in particular, surveys) are still the most widely used techniques for collecting empirical data in entrepreneurship and general organizational research (Crook et al., 2010), the level of granularity inherent in the discussed 


\section{Research Design and Construct Measurement}

Phase I: Triggers and venture idea generation

\section{Triggers}

- Desire to start

- Resource push

- Market pull

- Customer segment

- Customer need

Paths

- Intentional idea generation

- Accidental discovery

- Legacy
Diaries, participant observation and experiments (e.g., Amabile et al., 1996; Nijstad et al., 2002)

Examples:

- Experimental design to investigate the influence of triggers on venture idea generation; for example, provide subjects with idea generation tasks under different conditions (e.g., expose them to a customer need)

- Diary approach to have subjects note (1) their ideas in periodical intervals, and (2) how they arrived at their ideas

\section{Venture Ideas}

- Idea content

- Idea characteristics

- Quantity

- Quality

- Novelty

- Relatedness

Experiment, diaries, participant observation (e.g., Amabile et al., 1996;

Girotra et al., 2010; Kornish \& Ulrich, 2014; Nijstad et al., 2002)

Examples:

- Experimental design to investigate how different triggers and paths
Phase II: Venture opportunity development and exploitation lead to different characteristics of venture ideas

- Assessment of the initial idea and the dimensions of the venture concept which it covers (customer segment, customer needs, resources/ capabilities)

- Assessment of the depth of understanding of each element

- Real-time evaluation of idea characteristics by subjects themselves (using scales)

- Evaluation of ideas by others (e.g., expert raters, venture capitalists, customers indicating purchase intent, crowd)

- Evaluation by researchers (e.g., using existing scales and classification systems [SIC categories etc.])

\section{Venture Concept}

- Content of the venture concept

- Incubation process
Diaries, participant observation, mobile tracking (e.g., Clarysse \& Moray, 2004; Senyard, Baker, Steffens, \& Davidsson, 2014; Uy et al., 2010)

Examples:
Survey, interviews (e.g., Bhave, 1994; Gartner, Shaver, Carter, \& Reynolds, 2004; Hougaard, 2005; Schwartz \& Teach, 2000) Examples:

- Assessing the triggers by asking whether (1) subject had the specific desire to start a venture prior to having the venture idea, (2) a particular resource/capability existed and needed to be commercialized, or (3) a customer segment or customer need was identified first and then a solution

- Assessing mechanism of idea generation by asking whether initial venture idea (1) was the result of an intentional search process, (2) was discovered accidentally, or (3) was provided to the individual by someone else

Survey, interviews (e.g., Amabile et al., 1996; Baer, Kaufman, \& Gentile, 2004;

Baron \& Ensley, 2006; Gruber et al., 2013; Hill \& Birkinshaw, 2010)

Examples:

- Assessment of the initial idea and the dimensions of the venture concept which it covers (customer segment, customer needs, resources/ capabilities)

- Assessment of the depth of understanding of each element

- Evaluation of ideas by others (e.g., expert raters, venture capitalists, customers indicating purchase intent, crowd)

- Evaluation by researchers (e.g., using existing scales and classification systems [SIC categories etc.])

Survey, interviews (e.g., Zahra \& Covin, 1993) Examples:

- Assessment of the intensity of planning entrepreneurs engaged in prior 


\section{Table 3}

\section{Continued}

\section{Construct}

\section{Real-time/longitudinal}

Retrospective measurement measurement

\section{Evaluation}

- Desirability

- Feasibility

\section{Exploitation}

- Firm performance

- Pivoting
- Assessment of the depth of understanding of customer segment, customer needs, resources and capabilities

- Assessment of depth of understanding of more refined elements building on the venture concept (e.g., value proposition, competitive advantage, cost structure, revenue structure)

- Observing the founders over an extended period of time from idea generation to exploitation and beyond, and combine observatory data (notes) with surveys/interviews for background information

- Using diaries (e.g., using mobile technology) for subjects to track new insights or changes related to the venture concept (e.g., the number of pivots made or the degree of pivoting)

Experiment, diaries (e.g., Choi \& Shepherd, 2004; Haynie et al., 2009)

Examples:

- Experimental design, in particular conjoint analysis, to investigate which entrepreneurs evaluate which venture concepts as worth exploiting

- Multidimensional real-time evaluation of venture concepts and their evolution over time; for instance, matched with data on individuallevel factors captured via survey/ interview

Diaries, participant observation, mobile tracking (e.g., Aguinis \& Edwards, 2014; Clarysse \& Moray, 2004; Uy et al., 2010) Examples:

- Longitudinal real-time diary approach (e.g., using mobile technology) where entrepreneurs track pivoting of the dimensions of the venture concept (customer segment, customer needs, resources and capabilities)

- Observe the new venture over an extended period of time and collect data (notes and frequent interviews with the subjects) on changes to any of the dimensions of the venture concept to exploitation (formal business planning, target market and segment definition, definition of business model)

- Applying the Critical Incidence Technique (CIT) (Flanagan, 1954) to be able to retrospectively capture the most critical events during planning and incubation

- Assessing the number of pivots made during incubation
Survey, interviews (e.g., Bock et al., 2012; Dencker et al., 2009a, 2009b; Murphy et al., 1996)

Examples:

- Firm performance: established objective and subjective performance measures

- Retrospective assessment of venture concepts (snapshots) at different points in time

- Retrospective assessment of major changes to the venture concept (asking about changes in customer segment, customer need, resources and capabilities used) 
concepts, as well as the development process underlying these concepts, make it challenging, if not impossible, for scholars to fruitfully apply retrospective designs for their empirical assessment. As highlighted by Ployhart and Vandenberg (2010), "most theories in organizational sciences are either explicitly or implicitly longitudinal in nature," including retrospective approaches such as surveys about a specific time-point in the past and should therefore be tested using adequate longitudinal techniques instead of crosssectional approaches. Yet, retrospective reports may be useful for assessing individuallevel factors (e.g., human capital, cognitive style, situational context) and external factors (e.g., competition, market growth) that affect both the venture idea generation and the opportunity development process, as these elements capture facts that are less susceptible to recall biases and post hoc rationalization (Golden, 1992; Lohrke, Holloway, \& Woolley, 2010). This data may also serve as a complement to real-time data.

Given that real-time research designs can be of great value for assessing the early stages of the entrepreneurial process, I will be presenting a variety of methods because "calls for longitudinal methods have become a hallmark of our field" (McMullen \& Dimov, 2013, p.1481) and because these techniques are of particular relevance for the elements of the proposed framework. Real-time/longitudinal designs allow capturing finegrained data and understanding how processes unfold over time (Uy, Foo, \& Aguinis, 2010). Among the most widely used real-time designs are experiments and diaries. Experimental settings allow scholars to examine idea generation (e.g., Girotra et al., 2010) and opportunity evaluation (Haynie et al., 2009). For instance, in an experimental setup similar to the one by Girotra et al., researchers can provide subjects with an idea generation task and examine how different types of triggers impact idea-generation. A diary approach would enable researchers to capture the dynamic nature of the entrepreneurial process, as individuals report on their decisions, successes, and failures on a regular basis (e.g., Amabile, Barsade, Mueller, \& Staw, 2005). Poole, Van de Ven, Dooley, and Holmes (2000) offer an overview of process-oriented research methodologies.

Advances in communication technology (e.g., mobile phones or tablets with the support of apps) should serve as catalysts for more widespread adoption of real-time, longitudinal methods owing to the greater cost-effectiveness and simplified data collection (e.g., Aguinis \& Edwards, 2014; Bolger, Davis, \& Rafaeli, 2003). Such methods are used successfully in the medical arena, where doctors have started to monitor their patients in real time (Heron \& Smyth, 2010). Within the context of this framework, mobile technologybased diaries or experience sampling would allow scholars to collect fine-grained data on the early stages of firm creation in real time, and to match such data with data on the entrepreneur's context (e.g., location, time) (Scollon, Kim-Prieto, \& Diener, 2003; Uy et al., 2010).

For instance, in the context of entrepreneurship, it seems that the real-time methods may also be applied in less traditional research settings, such as start-up weekends, where typically a larger number of potential firm founders meet, develop venture ideas, and craft their venture concepts. Likewise, one may use such methods for venture competitions.

\section{Measuring the Venture Idea}

I have defined a venture idea as a preliminary and mostly incomplete mental representation of the venture concept. By linking venture ideas to the multidimensional construct of venture concepts, scholars may gain a better understanding of idea generation. This is because individuals may generate venture ideas on the basis of different triggers, which suggests that some elements of the venture idea (e.g., a technological resource) are already "given," while 
others still need to be determined. Moreover, individuals may also generate venture ideas that are more or less complete; hence, a multidimensional conceptualization allows scholars to assess such fine-grained patterns (Baron \& Ensley, 2006; Gaglio \& Katz, 2001).

These considerations correspond to current approaches in creativity and innovation research, especially those studies examining the generation and evaluation of product ideas (e.g., Girotra et al., 2010; Kornish \& Ulrich, 2014). However, research in these domains tends to be less systematic in classifying the content of ideas from a business perspective. Thus, an important feature of this novel conceptualization is that it provides unrestricted means of assessing the content of venture ideas and the subsequent shaping and refining of these ideas along the core dimensions of the venture concept.

Creativity and innovation literature have both offered a variety of retrospective and real-time/longitudinal research designs to capture different elements of this phase. Experimental designs have been widely used in the innovation literature to capture idea generation and show how different triggers influence idea generation (e.g., Girotra et al., 2010). Likewise, creativity literature embraces the diary approach and participant observations as a means to capture real-time information about why, when, and how individuals or teams generate new ideas (e.g., Amabile et al., 1996). Similarly, various methods have been developed to assess the different characteristics of newly generated ideas, including the quality, quantity, variety, or to demonstrate completeness regarding the different dimensions of the venture concept, such as expert ratings (e.g., Nijstad, Stroebe, \& Lodewijkx, 2002; Kornish \& Ulrich, 2014). Likewise, there exist a few retrospective approaches for capturing the venture idea generation stage (e.g., Hougaard, 2005). However, this is much less prevalent in the literature, most likely as a result of the retrospective bias that might largely affect the results in this particular stage of the process. Table 3 features approaches to empirically determining the triggers of idea generation, the paths of idea generation and the various characteristics of ideas, such as quality, quantity, and variety.

\section{Measuring the Venture Concept}

I define the venture concept as the simplified nascent-stage representation of a business model, including the customer segment, the customer need, and the resources and capabilities to be used in the future venture. The venture concept thus reflects an advanced understanding of the value-creation potential associated with the venture, and allows the entrepreneur to evaluate whether or not it is feasible and desirable to exploit the venture concept.

Accordingly, the measurement of the venture concept is built on the measurement of the venture idea, with the key difference being that it also captures the individual's increasing understanding of the core dimensions of the venture. This advanced understanding is reflected not only in how well the individual comprehends these core dimensions, but is also seen in key business issues which build on and extend these three dimensions, such as the value proposition, its competitive advantage, cost structure, and revenue structure (Osterwalder \& Pigneur, 2010). Yet, the extent to which individuals increase their understanding of the venture concept before engaging in exploitation is a personal choice (George \& Bock, 2012).

Both real-time/longitudinal and retrospective methods are discussed in Table 3, including the diary approach (e.g., Amabile et al., 1996) for tracking the changes being made to different dimensions of the venture concept over time, or using mobile-phone interfaces to allow entrepreneurs to keep track of things they have changed during a given time period (e.g., Aguinis \& Edwards, 2014). Another promising, yet time-consuming, approach is to observe entrepreneurs over a continuous period of time (e.g., Clarysse \& 
Moray, 2004). With regards to retrospective techniques, both surveys and interviews can be used for capturing the intensity of planning prior to exploitation (e.g., Zahra \& Covin, 1993). Moveover, these techniques can be used to apply the critical incidence technique (CIT) to determine or record the most critical events during planning and incubation (Flanagan, 1954). However, similar to idea generation, these retrospective techniques are prone to retrospection bias, which is why the longitudinal approach might be more promising. Again, examples of how these elements can be measured are provided in Table 3.

\section{Measuring the Venture Opportunity and Exploitation}

I have defined the venture opportunity as a favorable combination of endogenously shaped and exogenously given circumstances that make it both desirable and feasible for the entrepreneur to exploit a venture concept and to introduce a potentially value-adding offering into the marketplace. From the perspective of the entrepreneur, the venture opportunity thus exists if they arrive at a favorable assessment regarding the future prospects of the venture concept (McMullen \& Shepherd, 2006) — which corresponds to an ex ante evaluation and can be tested empirically using several measures (see Table 3). Specific techniques to capture the evaluation stage (the desirability and feasibility) can be done, for example, through experiments and more specifically a conjoint analysis (e.g., Choi \& Shepherd, 2004; Haynie et al., 2009). Moreover, retrospective survey-based or interview-based techniques can be used, using scales to rate the desirability (the perceived value) and the feasibility (the perceived ability) (e.g., Krueger \& Brazeal, 1994; Fitzsimmons \& Douglas, 2011). Techniques for analyzing the exploitation stage (e.g., firm performance or the degree of pivoting after the market entry), both longitudinal techniques such as diaries, participant observation, or mobile tracking (e.g., Aguinis \& Edwards, 2014; Clarysse \& Moray, 2004; Uy et al., 2010) and retrospective techniques such as surveys or interviews (e.g., Bock, Opsahl, George, \& Gann, 2012; Dencker et al., 2009a; 2009b; Murphy, Trailer, \& Hill, 1996) can be used.

In conclusion, a large variety of real-time/longitudinal and retrospective measurement techniques exist in the field of entrepreneurship and in adjacent fields of creativity and innovation management. While single-method approaches are always feasible, a mixed-method approach may be advisable in order to grasp the complex and inter-related concepts of the process. For example, while a longitudinal method may be used to trace the evolution of the venture idea through to exploitation, the founder's background and environmental factors can be assessed using a survey or interview. Also, a number of interviews might be conducted to approximate a "real-time" analysis without having to sit in and observe the founders in real-time.

\section{Agenda for Future Research on Ideas and Opportunities}

By distinguishing between the concepts of venture ideas and venture opportunities, by specifying the ways in which individuals or teams generate their venture ideas, by introducing the venture concept as a focal unit of analysis, and by emphasizing that ideas need to be transformed into venture concepts to form the basis for new venture creation, the framework opens up interesting avenues for future research (see Table 4).

On the one hand, researchers may focus on how individual-level and external factors affect the different phases of the process (i.e., idea generation, venture concept incubation and evaluation, and exploitation). Moreover, scholars can study the links among the main 


\section{Agenda for Future Research on Ideas and Opportunities}

Venture idea generation

Linking individual-level factors with venture idea generation

- How does prior experience (industry experience, startup experience, or breadth of functional knowledge) influence the path of venture idea generation and the type of venture ideas being generated?

- What is the influence of cognitive flexibility on the number and variety of generated venture ideas as well as on the quality of the venture idea?

Linking external factors with venture idea generation

- Does external pressure systematically modify the probability distribution of different paths of venture idea generation and if so how?

- Does an individual's environment systematically modify the probability distribution of different paths of venture idea generation and if so how?

Linking the path of venture idea generation to the venture idea

- To which extent does an individual's cognitive style influence the incubation and evaluation process?

- Does the path of venture idea generation influence the quality of the venture idea and if so how?

- Which path leads to more unique venture ideas?

\section{Venture opportunity development and exploitation}

Linking individual-level factors with venture opportunity development

- How does prior experience (e.g., industry experience, startup experience, or breadth of functional knowledge) influence the incubation and evaluation process (in time and complexity)?

- How does social identity affect the degree of experiential learning during incubation?

Linking external factors with venture opportunity development

- How does external (or situational) pressure influence the incubation (e.g., incubation time) and evaluation process (e.g., likelihood of positive evaluation)?

- How do entrepreneurs learn from industry incumbents in adapting a venture concept?

Venture opportunity exploitation

- What is the influence of the intensity of venture concept incubation on the degree of pivoting?

- To what extent will an individual's cognitive style influence the degree of pivoting?

- Will venture concepts that have been designed using both cognitive and experiential learning activities systematically outperform those that rely solely on cognitive analysis?

Longitudinal assessment from idea to opportunity

- Which individual and environmental factors lead to the greatest degree of variation up until exploitation?

- Which individual and environmental factors influence venture concept clarity at the time of first insight and how is it affected by the context?

- How does the venture concept clarity evolve over time from first insight to market entry and how do specific human and social capital factors influence this evolution?

- Does the time from venture idea to exploitation vary depending on the trigger of idea generation?

- How do different triggers and idea generation paths influence aspects of the venture concept or notions of incubation or evaluation?

- How do various activities for shaping and refining of the venture concept during the incubation stage relate to the evaluation stage?

- Is there a systematic link between the triggers of venture idea generation and the likelihood of a venture idea being turned into a venture opportunity and ultimately exploitation?

constructs, such as between venture idea generation and venture concept incubation, or between venture opportunity development and the exploitation stage.

On the other hand, scholars may embrace the aforementioned longitudinal study design and trace the evolution of an initial venture idea into a more complete venture concept over time. This is in line with several recent calls for more longitudinal studies (McMullen \& Dimov, 2013; Selden \& Fletcher, 2015). Researchers can, for example, assess the learning process of the entrepreneurs that collect missing pieces of information about the venture 
concept and as such, generate a clearer picture of the prospective future venture, and under which conditions they evaluate it as being both desirable and feasible to exploit the opportunity. In the following, I will briefly discuss some avenues for future research related to the specific phases of the process (venture idea generation, venture opportunity development, and exploitation) as well as longitudinal across-phase research designs.

\section{Venture Idea Generation}

By making the generation of venture ideas a focal construct in entrepreneurship research, scholars will be able to answer some of the recent calls for more work on the early stages of the entrepreneurial process (Davidsson, 2012; Hill \& Birkinshaw, 2010), and as such advance understanding of this "nucleus" of new venture creation on multiple fronts. In particular, based on insights from creativity and innovation research (e.g., Amabile et al., 1996; Girotra et al., 2010; Kornish \& Ulrich, 2014; Nijstad et al., 2002), scholars could examine how the antecedents and the contingent factors affect venture idea generation, thereby taking into account individual-level factors (e.g., human or social capital) and external factors, as well as the different types of triggers. Notably, these investigations might focus on both the idea generation process and its outcomes (the generated ideas) along several dimensions: the number of ideas, their quality, their variety, etc. A research design which is informed by creativity literature might lead to promising insights for entrepreneurship research. Yet, because venture idea generation occurs under partially different boundary conditions than the processes of idea generation typically studied in creativity research, findings from entrepreneurship have the potential to contribute to creativity literature as well.

Moreover, scholars might investigate whether some individuals more frequently arrive at venture ideas via a particular path, whether some paths possibly lead to better ideas, or even how different triggers affect idea generation. By temporally disentangling the early stages of the entrepreneurial process (Dimov, 2007b), scholars will also be able to study the evolution from venture idea to venture opportunity, thus answering some of the recent calls for more longitudinal studies in the field of entrepreneurship (e.g., McMullen \& Dimov, 2013).

\section{Venture Opportunity Development and Exploitation}

The venture opportunity development phase is comprised of the incubation (shape and refine, accumulate missing knowledge, etc.) and evaluation (desirability and feasibility) of the venture concept. Exploitation is the subsequent stage where the entrepreneur turns thoughts into action and starts creating a new venture. As in the case of venture idea generation, one can examine this phase from both a process perspective (e.g., pursued activities, incubation time, learning) as well as an outcome perspective (e.g., assessing how complete a venture concept is before individuals move to exploitation). Furthermore, scholars may take into account antecedents and contingent factors affecting this phase. This not only means that individual-level factors, such as experience, and external factors, including hostility among competitors or the general market environment, may be studied in relation to venture incubation and evaluation, but it can also mean that the venture idea generation phase can be related to the venture opportunity development phase. Likewise, entrepreneurs and entrepreneurial firms differ in how much they are embedded in and reach out to their social environment (e.g., customers and other relevant players) during opportunity development (Sarasvathy, 2001; Venkataraman et al., 2012), providing an 
interesting setting for studying the link between individual social identity, network engagement, and venture opportunity development. Moreover, researchers can look at how an entrepreneur's social embeddedness affects learning behavior during the development of the venture concept and the corresponding core dimensions.

As mentioned before, after gathering sufficient information and knowledge to assess whether it is desirable and feasible to create a new venture, an entrepreneur will move toward exploitation. Early decisions may shape processes and outcomes which occur later in new venture creation (Boeker, 1988). Hence, by examining the initial phases of new venture creation, one may identify compelling explanations for later-stage phenomena in entrepreneurship, including the extent to which entrepreneurs adapt (pivot) their concept (later business model) during the exploitation phase (Blank, 2013) and subsequent firm performance (Kornish \& Ulrich, 2014). It may therefore be interesting to study the link between different individual and environmental factors and entrepreneurial learning concerning the venture concept, its completeness as well as pivoting during exploitation.

\section{Longitudinal Assessment From Idea to Opportunity}

Besides the aforementioned "within-phase" research questions, there are a variety of interesting "across-phase" research questions that can be addressed by using a longitudinal research design. More specifically, scholars might perform longitudinal studies to follow the venture idea through the incubation and evaluation phase and assess the learning processes (learning about the venture's market, etc.) and the adaptations that take place. This is in line with claims for more longitudinal research in organizational sciences (McMullen \& Dimov, 2013; Ployhart \& Vandenberg, 2010; Selden \& Fletcher, 2015).

Particularly promising questions could be related to the clarity of the venture concept and its core dimensions at the different stages of the process and how different factors and conditions influence the process of learning and developing a clearer understanding of the prospective future venture over time. For example, a technology inventor might have a clear understanding of the technological resource at the time of ideation, but still lack an understanding of the market (customer segment and need). It is only with time that a clear picture of the future venture can be developed. Similarly, an individual might identify an unfulfilled need but still needs to develop an understanding for how to address it. It can be interesting to study the different individual and environmental factors that influence this process and how the triggers of venture ideas and the incubation phase influence this learning process.

\section{Summary}

Overall, these selected research questions illustrate how the main concepts discussed in the framework may be linked to generate novel insights about the early stages of new venture creation. Table 4 provides an overview of several potential research questions. Note, however, that by no means do these research questions exhaust the space of potentially important, hitherto unaddressed research questions which scholars may deduce from the proposed framework.

\section{Discussion and Conclusion}

The concept of "opportunities" has been widely studied in the field of entrepreneurship, leading to several alternative and, in part, conflicting perspectives. This article 
contributes to research by developing a framework which builds on and extends the notion that opportunities should not be seen as single insights, but rather as "something emerging through the continuous shaping and refining of (raw) ideas that are acted upon" (Davidsson, 2012; Dimov, 2007b, p. 713; Hill \& Birkinshaw, 2010; Shane, 2012).

Notably, by distinguishing between venture ideas and venture opportunities, and by underscoring the fact that raw ideas need to be developed into venture opportunities, the field of entrepreneurship is able to forge closer links with the neighboring domains of creativity and innovation research and, thus, to benefit from the rich bodies of knowledge on how ideas are generated and how innovations are brought to life. Yet, as discussed below, the transfer of knowledge to the field of entrepreneurship research does not have to be one-way, as the new venture creation setting allows for insight that can refine, extend, and inspire scholarly discourse in the fields of creativity and innovation alike.

By outlining the early phase of the new venture creation process and by developing refined constructs that capture key phenomena during this early phase, one of the core contributions of this article is to shed light on elements that can have a substantial influence on new firm creation, yet have hitherto been largely neglected in scholarly research. For instance, the paths of venture idea generation allow scholars to attain more systematic insights as to how the nuclei of emerging firms are generated, which paths lead to the best venture ideas and help designing improved pathways to venture idea generation. Likewise, by differentiating between the triggers of idea generation, scholars can develop detailed insights on the existing differences between the generation of demand-side and of supply-side ideas, and how those differences play out in the development of the venture concept (Jolly, 1997).

At the heart of the framework is the venture concept, which encompasses three fundamental business dimensions (Abell, 1980). The venture concept can serve as an important unit of analysis in entrepreneurship research which allows tracking the evolution of the new venture from the raw idea to exploitation and beyond. It also allows for capturing key pivoting activities. Furthermore, the venture concept can be seen as the basis from which more advanced and refined elements of a full-fledged business model are designed. Often, the entrepreneur already has an initial understanding of key business model elements, such as the value proposition, or the revenue- and cost structure (Osterwalder \& Pigneur, 2010). However, typically, these can only be specified and formulated in greater detail once the venture's resources and capabilities, the customer segments, and the served customer needs of a venture are known.

Furthermore, it is important to emphasize that the proposed framework developed in this article is open to both discovery and creation perspectives in entrepreneurship. In particular, suggestions for measuring focal constructs do not pre-impose any perspective on an entrepreneur's new firm creation activities, as these include what the entrepreneur has specified and how specifications for a venture evolve over time.

Improving the understanding of the early phases of new venture creation will also have important ramifications concerning our knowledge of the antecedents of new venture performance. As discussed, recent research in creativity and innovation indicates that the quality of the raw idea is a key determinant of new product performance (Kornish \& Ulrich, 2014). This major finding not only suggests the importance of distinguishing between ideas and opportunities in entrepreneurship research but also highlights the need to apply a refined set of concepts, methods, and measures to study the early phases of new venture creation. Ultimately, if the raw venture ideas make a difference for future performance, this would imply that individuals should invest more time and effort in idea generation. For instance, on the trail to reaching a better understanding of venture idea generation, research can help us understand why some individuals may come up with 
better ideas than others, and which actions are required to shape and refine a raw idea until it emerges as a promising opportunity.

One should not forget, however, that creativity and innovation research can also benefit from insights generated in entrepreneurship research. In particular, researching new ventures brings with it the advantage that processes of idea generation, venture concept incubation, and evaluation occur in a setting that is much less complex than the settings typically studied in innovation research (i.e., large firms). Thus, researchers will be able to assess some of the factors that affect these early phases (e.g., prior knowledge and experience) in a relatively more straightforward and also more reliable way when conducting research in the new firm setting. One example is that a smaller number of individuals shape this early phase as compared to potentially dozens of people affecting innovation in large firms. Beyond these methodological advantages, research in entrepreneurship could generate new insights for creativity and innovation literature because of its focus on venture ideas, which arguably form an important subclass of ideas in general. By examining the venture idea construct, for instance, one can distinguish between instances where the technology is the trigger, instances where the market need is the trigger, and yet other instances where only the desire for engaging in entrepreneurial activity exists. Because these different instances prescribe important boundaries for idea generation and define the missing element(s) for which idea(s) are sought, research which takes these points into account has the potential of leading to novel insights for creativity and innovation research.

The proposed framework can also be of value in the educational arena, as more and more entrepreneurship courses engage in experiential learning by requiring that students develop their own ventures (e.g., Kuratko, 2005). Moreover, various scholars have focused on ways of making the generation of venture ideas (quantity and quality) a key capability that ought to be taught in entrepreneurship classes (e.g., DeTienne \& Chandler, 2004). In this regard, the framework not only provides students with an overview of key concepts shaping early-stage venture creation, but may also inspire the design of curricula. For instance, a refined view of the early-stage venturing process may help educators develop courses that focus on distinct phases (e.g., venture idea generation) or that use particular triggers as starting points and ask the students to engage in idea generation as a result of these triggers.

Finally, many current examples of entrepreneurial activity focus on the role of entrepreneurs in addressing societal problems and challenges (Dacin, Dacin, \& Matear, 2010). While the theoretical development and discussion in this article have been anchored in for-profit venture creation, I believe that the proposed framework has the flexibility to apply to social entrepreneurship as well. Future research could look into any potential differences in detail. In any case, the detailed study of the early-stage new venture creation process is a fascinating challenge that promises to hold important insights which will not only advance entrepreneurship research but also that in neighboring research domains.

\section{REFERENCES}

Abell, D.F. (1980). Defining the business: The starting point of strategic planning. Englewood Cliffs, NJ: Prentice-Hall.

Afuah, A. (2003). Innovation management (2nd ed.). New York: Oxford University Press.

Afuah, A. \& Tucci, C.L. (2000). Internet business models and strategies: Text and cases. New York: MacGraw-Hill. 
Afuah, A. \& Tucci, C.L. (2012). Crowdsourcing as a solution to distant search. Academy of Management Review, 37, 355-375.

Aguinis, H. \& Edwards, J.R. (2014). Methodological wishes for the next decade and how to make wishes come true. Journal of Management Studies, 51, 143-174.

Alsos, G. \& Kaikkonen, V. (2004). Opportunity recognition and prior knowledge: A study of experienced entrepreneurs. Paper presented at the NCSB Conference, Tromso, Norway.

Alvarez, S. \& Barney, J. (2007). Discovery and creation: Alternative theories of entrepreneurial action. Strategic Entrepreneurship Journal, 1, 11-26.

Alvarez, S. \& Barney, J. (2013). Epistemology, opportunities, and entrepreneurship: Comments on Venkataraman et al. (2012) and Shane (2012). Academy of Management Review, 38, 154-157.

Alvarez, S.A., Barney, J.B., \& Anderson, P. (2013). Forming and exploiting opportunities: The implications of discovery and creation processes for entrepreneurial and organizational research. Organization Science, 24, 301-317.

Amabile, T.M. (1996). Creativity and innovation in organizations. Harvard Business School, 5, 396-239.

Amabile, T.M., Barsade, S.G., Mueller, J.S., \& Staw, B.M. (2005). Affect and creativity at work. Administrative Science Quarterly, 50, 367-403.

Amabile, T.M., Conti, R., Coon, H., Lazenby, J., \& Herron, M. (1996). Assessing the work environment for creativity. Academy of Management Journal, 39, 1154-1184.

Ardichvili, A., Cardozo, R., \& Ray, S. (2003). A theory of entrepreneurial opportunity identification and development. Journal of Business Venturing, 18, 105-123.

Baer, J., Kaufman, J.C., \& Gentile, C.A. (2004). Extension of the consensual assessment technique to nonparallel creative products. Creativity Research Journal, 16, 113-117.

Baker, T. \& Nelson, R. (2005). Creating something from nothing: Resource construction through entrepreneurial bricolage. Administrative Science Quarterly, 50, 329-366.

Baron, R. (2006). Opportunity recognition as pattern recognition. Academy of Management Perspective, 20, 104-119.

Baron, R. \& Ensley, M. (2006). Opportunity recognition as the detection of meaningful patterns: Evidence from comparisons of novice and experienced entrepreneurs. Management Science, 52, 1331-1334.

Bhave, M.P. (1994). A process model of entrepreneurial venture creation. Journal of Business Venturing, 9, 223-242.

Blank, S.G. (2013). Four steps to the epiphany (2nd ed.). Somerset, TX: K\&S Ranch.

Blank, S. \& Dorf, B. (2012). The startup owner's manual: The step-by-step guide for building a great company. Pescadero, CA: K\&S Ranch, Inc.

Bock, A.J., Opsahl, T., George, G., \& Gann, D.M. (2012). The effects of culture and structure on strategic flexibility during business model innovation. Journal of Management Studies, 49, 279-305.

Boeker, W. (1988). Organizational origins: Entrepreneurial and environmental imprinting at the time of founding. In G. Carroll (Ed.), Ecological models of organizations (pp. 33-51). Cambridge, MA: Ballinger Publishing.

Bolger, N., Davis, A., \& Rafaeli, E. (2003). Diary methods: Capturing life as it is lived. Annual Review of Psychology, 54, 579-616. 
Brown, T. (2008). Design thinking. Harvard Business Review, 86, 84-92.

Chandler, G., Dahlqvist, J., \& Davidsson, P. (2002). Opportunity recognition processes: A taxonomy and outcome implications. In W.D. Bygrave, C.G. Brush, P. Davidsson, J. Fiet, P.G. Greene, R.T. Harrison, M. Lerner, G.D. Meyer, J. Sohl, \& A. Zacharakis (Eds.), Frontiers of entrepreneurship research (pp. 38 48). Wellesley, MA: Babson College.

Chandler, G., DeTienne, D., \& Lyon, D. (2003). Outcome implications of opportunity creation/discovery processes. Frontiers of entrepreneurship research. Available at http://fusionmx.babson.edu/entrep/fer/ BABSON2003/XVI/XVI-P1/XVI-P1.html, accessed 17 June 2016.

Chesbrough, H.W. (2003). Open innovation: The new imperative for creating and profiting from technology. Boston, MA: Harvard Business School Press.

Chesbrough, H.W. \& Rosenbloom, R.S. (2002). The role of business models in capturing value from innovation: Evidence from Xerox's corporation technological spin-off companies. Industrial and Corporate Change, 11, 529-555.

Choi, Y.R., Lévesque, M., \& Shepherd, D.A. (2008). When should entrepreneurs expedite or delay opportunity exploitation? Journal of Business Venturing, 23(3), 333-355.

Choi, Y.R. \& Shepherd, D.A. (2004). Entrepreneurs' decisions to exploit opportunities. Journal of Management, 30, 377-395.

Churchill, N. \& Lewis, V. (1983). The five stages of business growth. Harvard Business Review, 61, $30-50$.

Clarysse, B. \& Moray, N. (2004). A process study of entrepreneurial team formation: The case of a research-based spin-off. Journal of Business Venturing, 19, 55-79.

CNBC. (2005). The Big Idea. Available at www.youtube.com/watch? $v=R W j F s W L P \_s k$, accessed 4 November 2012.

Cooper, R.G. (1988). Winning at new products. London: Kogan Page.

Corbett, A. (2005). Experiential learning within the process of opportunity identification and exploitation. Entrepreneurship Theory and Practice, 29, 473-491.

Crook, T.R., Shook, C.L., Morris, M.L., \& Madden, T.M. (2010). Are we there yet? An assessment of research design and construct measurement practices in entrepreneurship research. Organizational Research Methods, 13, 192-206.

Cropley, A.J. (2000). Defining and measuring creativity: Are creativity tests worth using? Roeper Review, $23,72-79$.

Csikszentmihalyi, M. (1996) Creativity. New York: HarperCollins.

Dacin, P.A., Dacin, M.T., \& Matear, M. (2010). Social entrepreneurship: Why we don't need a new theory and how we move forward from here. Academy of Management Perspectives, 24, 37-57.

Davidsson, P. (2012). Entrepreneurial opportunity and the entrepreneurship nexus: A reconceptualization. Paper presented at the Annual Meeting of the Academy of Management.

Davidsson, P. \& Wiklund, J. (2001). Levels of analysis in entrepreneurship research: Current research practice and suggestions for the future. Entrepreneurship Theory and Practice, 25, 81-100.

Dencker, J.C., Gruber, M., \& Shah, S.K. (2009a). Individual and opportunity factors influencing job creation in new firms. Academy of Management Journal, 52, 1125-1147. 
Dencker, J.C., Gruber, M., \& Shah, S.K. (2009b). Pre-entry knowledge, learning, and the survival of new firms. Organization Science, 20, 516-537.

DeTienne, D.R. \& Chandler, G.N. (2004). Opportunity identification and its role in the entrepreneurial classroom: A pedagogical approach and empirical test. Academy of Management Learning and Education, 3(3), 242-257.

Dew, N. (2009). Serendipity in entrepreneurship. Organization Studies, 30, 735-753.

Dimov, D. (2007a). From opportunity insight to opportunity intention: The importance of personsituation learning match. Entrepreneurship Theory and Practice, 31, 561-583.

Dimov, D. (2007b). Beyond the single person, single insight attribution in understanding entrepreneurial opportunities. Entrepreneurship Theory and Practice, 31, 713-731.

Dyson, J. (2003). Against the odds: An autobiography. New York: Texere.

Eckhardt, J. \& Shane, S. (2013). Response to the commentaries: The individual-opportunity (IO) nexus integrates objective and subjective aspects of entrepreneurship. Academy of Management Review, 38, 160-163.

Fitzsimmons, J.R. \& Douglas, E.J. (2011). Interaction between feasibility and desirability in the formation of entrepreneurial intentions. Journal of Business Venturing, 26, 431-440.

Flanagan, J.C. (1954). The critical incident technique. Psychological Bulletin, 51, 327-358.

Friedel, R.D., Israel, P., \& Finn, B.S. (1986). Edison's electric light: Biography of an invention. New Brunswick, NJ: Rutgers University Press.

Gaglio, C. \& Katz, J. (2001). The psychological basis of opportunity identification: Entrepreneurial alertness. Small Business Economics, 16, 95-111.

Gartner, W.B., Shaver, K.G., Carter, N.M., \& Reynolds, P.D. (2004). The handbook of entrepreneurial dynamics: The process of business creation. Thousand Oaks, CA: Sage Publications.

Garud, R. \& Gehman, J. (2012). Metatheoretical perspectives on sustainability journeys: Evolutionary, relational and durational. Research Policy, 41, 980-995.

Garud, R. \& Giuliani, A.P. (2013). A narrative perspective on entrepreneurial opportunities. Academy of Management Review, 38, 157-160.

George, G. \& Bock, A.J. (2012). Models of opportunity: How entrepreneurs design firms to achieve the unexpected. Cambridge: Cambridge University Press.

Girotra, K., Terwiesch, C., \& Ulrich, K.T. (2010). Idea generation and the quality of the best idea. Management Science, 56, 591-605.

Golden, B.R. (1992). Research notes. The past is the past—or is it? The use of retrospective accounts as indicators of past strategy. Academy of Management Journal, 35, 848-860.

Gruber, M., MacMillan, I.C., \& Thompson, J.D. (2013). Escaping the prior knowledge corridor: What shapes the number and variety of market opportunities identified before market entry of technology startups? Organization Science, 24, 280-300.

Hansen, D.J., Shrader, R., \& Monllor, J. (2011). Defragmenting definitions of entrepreneurial opportunity. Journal of Small Business Management, 49, 283-304.

Haynie, J.M., Shepherd, D.A., \& McMullen, J.S. (2009). An opportunity for me? The role of resources in opportunity evaluation decisions. Journal of Management Studies, 46, 337-361. 
Heron, K.E. \& Smyth, J.M. (2010). Ecological momentary interventions: Incorporating mobile technology into psychosocial and health behaviour treatments. British Journal of Health Psychology, 15, 1-39.

Hill, S.A. \& Birkinshaw, J.M. (2010). Idea sets: Conceptualizing and measuring a new unit of analysis in entrepreneurship research. Organizational Research Methods, 131, 85-113.

Hills, G., Lumpkin, G., \& Singh, R. (1997). Opportunity recognition: Perceptions and behaviors of entrepreneurs. Frontiers of Entrepreneurship Research, 17, 168-182.

Hougaard, S. (2005). The business idea: The early stages of entrepreneurship. Berlin, Germany: Springer.

Jolly, V.K. (1997). Commercializing new technologies. Boston: Harvard Business School Press.

Jones, C.F. (2011). Accidents may happen. New York: Delacorte Press.

Kaish, S. \& Gilad, B. (1991). Characteristics of opportunities search of entrepreneurs versus executives: Sources, interests, general alertness. Journal of Business Venturing, 6, 45-61.

Kirzner, I. (1997). Entrepreneurial discovery and the competitive market process: An Austrian approach. Journal of Economic Literature, 35, 60-85.

Koller, R. (1988). On the source of entrepreneurial ideas. Frontiers of Entrepreneurship Research. Available at http://fusionmx.babson.edu/entrep/fer/front_88.html, accessed 17 June 2016.

Kornish, L. \& Ulrich, K.T. (2014). "The importance of the raw idea in innovation: Testing the sow's ear hypothesis." Journal of Marketing Research, 51(1), 14-26.

Krueger, N.F. (1993). The impact of prior entrepreneurial exposure on perceptions of new venture feasibility and desirability. Entrepreneurship Theory and Practice, 18(1), 5-21.

Krueger, N. \& Brazeal, D. (1994). Entrepreneurial potential and potential entrepreneurs. Entrepreneurship Theory and Practice, 18, 91-91.

Kuratko, D.F. (2005). The emergence of entrepreneurship education: Development, trends, and challenges. Entrepreneurship Theory and Practice, 29, 577-598.

Lohrke, F.T., Holloway, B.B., \& Woolley, T.W. (2010). Conjoint analysis in entrepreneurship research a review and research agenda. Organizational Research Methods, 13, 16-30.

Lumpkin, G.T., Hills, G., \& Shrader, R. (2004). Opportunity recognition. In H.P. Welsch (Ed.), Entrepreneurship: The way ahead (pp. 86-103). New York: Routledge.

Marvel, M.R. (2013). Human capital and search-based discovery. Entrepreneurship Theory and Practice, 37, 403-419.

McGrath, R.G. \& MacMillan, I.C. (2000). The entrepreneurial mindset: Strategies for continuously creating opportunity in an age of uncertainty. Boston, MA: McGraw-Hill.

McMullen, J.S. \& Dimov, D. (2013). Time and the entrepreneurial journey: The problems and promise of studying entrepreneurship as a process. Journal of Management Studies, 50(8), 1481-1512.

McMullen, J. \& Shepherd, A. (2006). Entrepreneurial action and the role of uncertainty in the theory of the entrepreneur. Academy of Management Review, 31, 132-152.

Murphy, P. (2011). A 2x2 conceptual foundation for entrepreneurial discovery theory. Entrepreneurship Theory and Practice, 35, 359-374.

Murphy, G.B., Trailer, J.W., \& Hill, R.C. (1996). Measuring performance in entrepreneurship research. Journal of Business Research, 36, 15-23. 
Nijstad, B.A., Stroebe, W., \& Lodewijkx, H.F. (2002). Cognitive stimulation and interference in groups: Exposure effects in an idea generation task. Journal of Experimental Social Psychology, 38, 535-544.

Osborn, A.F. (1942). How to think up. New York: McGraw-Hill.

Osterwalder, A. \& Pigneur, Y. (2010). Business model generation—A handbook for visionaires, game changers, and challengers. New York: Wiley.

Ozgen, E. \& Baron, R. (2007). Social sources of information in opportunity recognition: Effects of mentors, industry networks, and professional forums. Journal of Business Venturing, 22, 174-192.

Pederson, J.P. (2005). International directory of company histories (Vol. 67). Farmington Hills, MI: St. James Press.

Penrose, E.T. (1959). The theory of the growth of the firm. Oxford: Oxford University Press.

Ployhart, R.E. \& Vandenberg, R.J. (2010). Longitudinal research: The theory, design, and analysis of change. Journal of Management, 36, 94-120.

Poole, M.S., Van de Ven, A.H., Dooley, K., \& Holmes, M. (2000). Organization change and innovation processes: Theory and methods for research. New York: Oxford University Press.

Ries, E. 2011. The lean startup: How today's entrepreneurs use continuous innovation to create radically successful businesses. New York: Crown Business, Random House.

Sarasvathy, S. (2001). Causation and effectuation: Toward a theoretical shift from economic inevitability to entrepreneurial contingency. Academy of Management Review, 26, 243-263.

Sarasvathy, S.D., Dew, N., Velamuri, S.R., \& Venkataraman, S. (2010). Three views of entrepreneurial opportunity. In Z.J. Acs \& D.B. Audretsch (Eds.), Handbook of entrepreneurship research (pp. 77-98). New York: Springer.

Schilling, M.A. (2013). Strategic management of technological innovation. New York: McGraw-Hill.

Schück, H. \& Sohlman, R. (1929). The life of Alfred Nobel. London: Heinemann.

Schwartz, R.G. \& Teach, R.D. (2000). A model of opportunity recognition and exploitation: An empirical study of incubator firms. Journal of Research in Marketing and Entrepreneurship, 2, 93-107.

Scollon, C.N., Kim-Prieto, C., \& Diener, E. (2003). Experience sampling: Promises and pitfalls, strengths and weaknesses. Journal of Happiness Studies, 4, 5-34.

Selden, P.D. \& Fletcher, D.E. (2015). The entrepreneurial journey as an emergent hierarchical system of artifact-creating processes. Journal of Business Venturing, 30(4), 603-615.

Senyard, J., Baker, T., Steffens, P., \& Davidsson, P. (2014). Bricolage as a path to innovativeness for resource-constrained new firms. Journal of Product Innovation Management, 31, 211-230.

Shane, S. (2003). A general theory of entrepreneurship: The individual-opportunity nexus. Northampton, MA: E. Elgar.

Shane, S. (2012). Reflections on the 2010 AMR decade award: Delivering on the promise of entrepreneurship as a field of research. Academy of Management Review, 37, 10-20.

Shane, S. \& Venkataraman, S. (2000). The promise of entrepreneurship as a field of research. Academy of Management Review, 25, 217-226.

Short, J.C., Ketchen, D.J., Shook, C.L., \& Ireland, R.D. (2010). The concept of "opportunity" in entrepreneurship research: Past accomplishments and future challenges. Journal of Management, 36, 40-65. 
Sieger, P., Fueglistaller, U., \& Zellweger, T. (2014). Student entrepreneurship across the globe: A look at intentions and activities. St. Gallen: Swiss Research Institute of Small Business and Entrepreneurship at the University of St. Gallen (KMU-HSG).

Singh, R. (2000). Entrepreneurial opportunity recognition through social networks. New York: Routledge.

Smith, G.F. (1998). Idea-generation techniques: A formulary of active ingredients. Journal of Creative Behavior, 32, 107-134.

Smith, B., Matthews, C.H., \& Schenkel, M.T. 2005. The search for and discovery of different types of entrepreneurial opportunities: The effects of tacitness and codification. Paper presented at the Babson College Entrepreneurship Research Conference (BCERC), Boston College.

Sternberg, R. \& O'Hara, L. (1999). Creativity and intelligence. In R. Sternberg (Ed.), Handbook of creativity) pp. 251-273). Cambridge: Cambridge University Press.

Suddaby, R. (2010). Editor's comments: Construct clarity in theories of management and organization. Academy of Management Review, 35, 346-357.

Uy, M.A., Foo, M.D., \& Aguinis, H. (2010). Using experience sampling methodology to advance entrepreneurship theory and research. Organizational Research Methods, 13, 31-54.

Van de Ven, A.H., Polley, D.E., Garud, R., \& Venkataraman, S. (1999). The innovation journey. New York: Oxford University Press.

Venkataraman, S. (1997). The distinctive domain of entrepreneurship research: An editor's perspective. Advances in Entrepreneurship, Firm Emergence, and Growth, 3, 119-138.

Venkataraman, S., Sarasvathy, S.D., Dew, N., \& Forster, W.R. (2012). Reflections on the 2010 AMR decade award: Whither the promise? Moving forward with entrepreneurship as a science of the artificial. Academy of Management Review, 37, 21-33.

Vogel, P. \& Fischler-Strasak, U. (2014). Fostering sustainable innovation within organizations. In C. Weidinger, F. Fischler, \& R. Schmidpeter (Eds.), Sustainable entrepreneurship (pp. 191-205). Berlin: Springer.

Ward, T.B. (2004). Cognition, creativity, and entrepreneurship. Journal of Business Venturing, 19, 173-188.

Weick, K.E. (1989). Theory construction as disciplined imagination. Academy of Management Review, $14,516-531$.

Zahra, S.A. \& Covin, J.G. (1993). Business strategy, technology policy and firm performance. Strategic Management Journal, 14, 451-478.

Zbaracki, M.J. (1998). The rhetoric and reality of total quality management. Administrative Science Quarterly, 43, 602-636.

Dr. Peter Vogel is the assistant professor for technology entrepreneurship and managing director Center for Entrepreneurship, Institute of Technology Management, University of St. Gallen, Dufourstrasse 40a, 9000 St. Gallen, Switzerland.

I gratefully acknowledge the help of my former PhD supervisor, Prof. Marc Gruber (EPFL). He has helped me tremendously in the process of shaping and advancing this paper. I also want to thank my other PhD committee members, Prof. Christopher Tucci (EPFL), Prof. John Dencker (Northeastern), and Prof. Jörn Block (University of Trier) for their insightful comments. Last but not least, I would like to thank my sister, Susanna Vogel, for having helped me with the design work of the figures. 